\title{
Neurociência: memória e funções executivas na articulação entre língua portuguesa e consciência política
}

\author{
Neuroscience: memory and executive functions on the relationship between \\ portuguese language teaching and political awareness
}

\author{
Aline Lorandi \\ Flávia Azambuja
}

Universidade Federal do Pampa - UNIPAMPA - Bagé - Rio Grande do Sul - Brasil

\begin{abstract}
Resumo:Este artigo pretende relatar a elaboração e aplicação de um projeto de ensino com o tema "política", trabalhando com diferentes gêneros textuais, que alie os conhecimentos de Língua Portuguesa e de Neurociência, com ênfase em aspectos ligados à memória e às funções executivas, com o intuito de obter o sucesso do aluno nos processos de ensino e de aprendizagem. Trata-se de uma pesquisa-ação crítica. Os resultados apresentados são: ideias acerca do projeto de ensino, as inferências durante a aplicação do projeto e os testes de consolidação na memória e de verificação da aplicabilidade do trabalho com as funções executivas por meio de uma roda de conversa orientada. Por fim, este trabalho evidencia a importância da Neurociência com uma aliada da Educação. Ciência que nos ajuda a pensar em estratégias que consideram o funcionamento do cérebro e, portanto, visam ao sucesso do aluno nos processos de ensino e de aprendizagem.
\end{abstract}

Palavras-chave:Neuroeducação. Consciência Política. Ensino de Língua Portuguesa.

Abstract: In this paper, we propose a teaching project based on the theme of politics in which we work on various genres putting together areas like Portuguese and Neuroscience. In Neuroscience we specifically work with memory and executive functions aiming the student success in the processes of teaching and learning. The research methodology is a critical action research. We do so for teachers to rethink their teaching practices. The results presented here embrace the teaching project, the inferences during the implementation of the teaching project, and the memory consolidation test by a group conversation. In doing so, we argue for the importance of Neuroscience as an ally to Education to help us think of strategies that consider the functioning of the brain and, therefore, enhance student success.

Keywords: Neuroeducation. Political Awareness.Portuguese Laguage Teaching.

\section{Introdução}

Este artigo tem por objetivo evidenciar a importância da Neurociência, que é uma ciência relativamente nova, e a sua relação com a Educação, iniciada nos anos 2000, o que demonstra a importância desta pesquisa, que pode contribuir muito para aprimorar a prática docente. Pensar em metodologias que almejem ao sucesso nos processos de ensino e de aprendizagem considerando a Neurociência significa refletir sobre estratégias que respeitem o funcionamento cerebral e que tenham o foco na aprendizagem. É fundamental salientar que a Neurociência não se propõe a ser uma solução mágica a todos os problemas educacionais. No entanto, esta ciência pode explicar metodologias que alcançam o sucesso nos processos de ensino e de aprendizagem, tornando tais processos embasados 
em uma teoria que tome o funcionamento do cérebro como base. Além disso, a Neurociência pode ajudar a pensar em alternativas para metodologias que não alcançam o sucesso nos processos de ensino e de aprendizagem.

Esta pesquisa originou um projeto de ensino com o tema "política" e os subtemas "manifestações populares" e "manipulação da informação", com gêneros textuais variados e análise linguística de acordo com os gêneros. Todas as atividades foram ancoradas na Neurociência, assim como a sua posterior aplicação, o que contribui para a diversidade de atividades, estímulos e recursos.

Houve um recorte na pesquisa pela limitação de tempo dedicado à pesquisa. Portanto, demos um enfoque maior com relação à memória e funções executivas. Os aspectos da emoção, da motivação e da atenção foram considerados tanto na elaboração quanto na aplicação do projeto de ensino.

A pesquisa deu origem a três hipóteses. A primeira hipótese diz respeito à temática do projeto que vai ao encontro dos interesses dos adolescentes que passariam a se interessar por conhecimentos mais abstratos. Outra hipótese se refere à conexão temática do projeto, já que, segundo a Neurociência o cérebro seleciona as informações de maneira conectada, o que facilitaria a consolidação na memória. A última hipótese tem relação com as atividades do projeto como um todo ao visar o funcionamento do cérebro se obteria resultados mais satisfatórios nos processos de ensino e de aprendizagem.

O objetivo geral foi propor e aplicar um projeto de ensino que alie os conhecimentos em Língua Portuguesa e Neurociência com a consciência política. Os principais objetivos específicos foram: implementar um projeto de ensino que almejasse ao cumprimento de pequenas tarefas para trabalhar as funções executivas e utilizar de diferentes estímulos e recursos para consolidar os conhecimentos na memória.

O artigo está organizado em três seções: a primeira é a Revisão da Literatura, em que apresentamos as relações entre Neurociência e
Educação, a importância da memória e das funções executivas e o ensino de Língua Portuguesa. A segunda apresenta a metodologia, uma pesquisaação crítica. Por fim, a terceira traz os resultados com ideias sobre o projeto de ensino, inferências sobre a aplicação e testes de verificação da consolidação na memória e aplicabilidade do trabalho com as funções executivas.

Este artigo é pioneiro na medida em que traz propostas metodológicas que podem auxiliar os professores tanto na utilização das mesmas quanto na reflexão de sua prática docente em uma área nova e tão pouco explorada no Brasil.

\section{Revisão da literatura}

\subsection{Neurociência e Educação}

A Neurociência é uma ciência interdisciplinar que contribui para com diversas áreas do conhecimento, tais como psicologia, medicina, dentre outras. É uma ciência que estuda o funcionamento cerebral, os comportamentos, as funções cognitivas entre outros interesses (Cosenza; Guerra, 2011). A relação com a Educação surgiu a partir do momento em que os cientistas perceberam que, ao aproveitar os conhecimentos sobre o funcionamento cerebral, ter-se-ia um desempenho mais eficaz nos processos de ensino e de aprendizagem.

Educar é proporcionar oportunidades e/ou o que nos proporciona $\operatorname{prazer}(\ldots)$. Aprendizagem, por sua vez, requer várias funções mentais como atenção, memória, percepção, emoção, função executiva, entre outras. E, portanto, depende do cérebro. (GUERRA, 2011, p. 107)

Dentre os diversos aspectos estudados pela Neurociência que nos ajudam a entender a aprendizagem, optamos por questões de limitação de tempo deste trabalho, por fazer um recorte em que enfocamos na memória e nas funções executivas. No entanto, os aspectos da Neurociência relacionam-se entre si, portanto atenção, motivação e emoção não foram desconsiderados na elaboração e na aplicação do projeto de ensino. A Neurociência nos mostra, por 
exemplo, que o aspecto da atenção e da memória estão intimamente ligados, já que é mais provável que apreendamos um determinado conhecimento se direcionarmos nosso foco atencional para ele. Relacionado ao aspecto da atenção está a emoção, pois costumamos atentar ao que nos emociona positivamente e, por sua vez, informações ligadas a emoções positivas costumam consolidar-se na memória com maior facilidade. A motivação é um aspecto que poderia ser mais explorado na escola, já que um aluno motivado, desafiado, sente mais vontade de aprender. O professor que utiliza tais conhecimentos sente-se mais seguro por estar embasado em uma teoria. Além disso, o professor determina com mais clareza os objetivos que quer e que pode atingir, o que facilita o monitoramento dos alunos e o seu próprio monitoramento.

A escolha por trabalhar funções executivas neste trabalho deve-se ao fato de que esse aspecto parece ser negligenciado pela escola, sendo delegado somente à família. No entanto, são funções essenciais para a vida escolar e para a vivência em sociedade. Ao longo deste trabalho, desenvolveremos com maior profundidade o que são as funções executivas. Com relação à memória, esta foi escolhida por sua relação com a aprendizagem, já que só podemos considerar algo como aprendido se podemos rememorá-lo. Começaremos pela abordagem da memória.

\subsection{Memória}

A memória é um dos aspectos mais importantes da Neurociência nos processos de ensino e de aprendizagem. E um dos estudiosos mais influentes no Brasil sobre o assunto, se não o mais influente, é Ivánlzquierdo, por isso trazemos um conceito de memória a partir do entendimento desse renomado autor.

\footnotetext{
"Memória" significa aquisição, formação, conservação e evocação de informações. A aquisição é também chamada de aprendizado ou aprendizagem: só se "grava" aquilo que foi aprendido. (IZQUIERDO, 2011, p. 11).
}

O conceito de memória proposto por Ivánlzquierdo evidencia a estreita ligação entre memória e Educação, portanto só podemos considerar uma informação como aprendida quando podemos lembrar-nos dela.

Existem inúmeras subcategorias de memórias e, no presente trabalho, vamos nos ater somente àquelas que receberam mais atenção no projeto de ensino, por terem-se mostrado mais pertinentes nos processos de ensino e de aprendizagem ${ }^{1}$.

\subsubsection{Memória de Trabalho}

Esse tipo de memória está ligado à manipulação de informações, é onde se encontram os arquivos que estão sendo usados (Matlin, 2004). A memória de trabalho também funciona como um arquivo de curto prazo; quando guardamos um número de telefone enquanto discamos, por exemplo, estamos utilizando essa memória. Além disso, a memória de trabalho tem a finalidade de nos orientar, saber onde estamos ou o que estamos fazendo.

\subsubsection{Memórias Declarativas e Memórias Procedurais}

Memórias declarativas são as que adquirimos de forma consciente e podemos falar sobre elas. A memória declarativa é muito valorizada no âmbito escolar, já que precisamos falar sobre nossos conhecimentos na escola.

As memórias procedurais são memórias adquiridas de forma inconsciente, como a que utilizamos para amarrar os sapatos.

\subsubsection{Memória de Curta e de Longa Duração}

A memória de curta duração é um tipo de memória que dura de alguns segundos até algumas horas. Já a memória de longa duração pode durar meses, alguns anos ou até a vida toda.

\footnotetext{
${ }^{1}$ Para um estudo mais aprofundado das categorias, ler (AZAMBUJA, 2014).
} 
O professor espera que os conteúdos trabalhados em aula se consolidem na memória de longo prazo dos alunos, portanto, ele deve estimular a metacognição, ou seja, a consciência sobre os próprios processos mentais. Nesses processos estão incluídos a metacompreensão, capacidade de ter consciência sobre o que entendemos, e a metamemória, consciência do que está consolidado na memória (Matlin, 2003). Assim, o aluno poderia investir menos tempo no que já está consolidado na memória e mais tempo em superar suas dificuldades.

\subsection{Funções Executivas}

As Funções Executivas (FEs) são constituídas por um conjunto de habilidades, dentre as quais estão: o planejamento, o controle inibitório, a sensibilidade a comportamentos socialmente aceitáveis, o monitoramento do próprio desempenho, a flexibilização cognitiva, a tomada de decisões, o estabelecimento de metas, a avaliação de riscos e a correção de erros (Corso, 2013).

As FEs são fundamentais para o nosso cotidiano, já que precisamos diariamente nos planejar, controlar impulsos e corrigir erros. A importância dessas habilidades também se dá no contexto escolar, pois o aluno deve saber se organizar, monitorar e corrigir erros. Portanto é um papel do professor, além da família, desenvolver e/ou aprimorar as funções executivas.

Um dos papeis do professor é pensar estratégias para 0 desenvolvimento das FEs. Obviamente o professor não pode orientar-se somente por aspectos físicos e biológicos, é necessário que se considere o aspecto humano. No entanto, os professores têm como base uma formação humanística, o que parece não ser suficiente para as demandas deste milênio, portanto a Neurociência pode ser uma aliada importante para pensar em estratégias que visem ao aprimoramento dos processos de ensino e de aprendizagem (COSENZA; GUERRA, 2011).

\subsection{0 ensino de Língua Portuguesa}

A concepção de língua adotada nesse artigo é como uma forma de interação, já que o falante é capaz de realizar ações que só são possíveis por meio da língua (Geraldi, 2006).

O trabalho com textos nos permite trabalhar a língua como uma forma de interação, visto que o texto permite estudar a gramática de forma contextualizada, refletindo sobre a construção de sentidos e não simplesmente a partir de nomenclaturas. Não encontramos trabalhos que relacionem Neurociência e ensino de Língua Portuguesa, por isso apresentamos essa proposta a partir de nossas inferências.

Inicialmente, pensamos que o projeto deveria ser temático, já que ajudaria a estabelecer conexões durante todo o projeto. Além disso, consideramos o cérebro adolescente para a escolha do tema, pois esta é uma fase em que os alunos interessam-se por temas mais abstratos, como a "política". A partir do tema, escolhemos os textos, os mais variados possíveis e que fizessem parte do cotidiano dos alunos. Assim, pensamos em tiras cômicas, notícias, artigos de opinião, roteiros, resumos, sinopses, piadas e músicas.

A análise linguística foi pensada de acordo com cada gênero textual. Nas tiras cômicas, optamos por trabalhar com intertextualidade e polifonia. A intertextualidade, em nosso entendimento, apresentase por meio da referência ou incorporação de outros textos e obras. Tal referência pode se dar por meio de textos diversos, tais como: uma imagem, uma música, um dito popular, entre outros (Barros; Fiorin, 1999 apud Zani, 2003). Os intertextos são normalmente identificados, já que fazem parte da memória social de uma coletividade (Koch; Elias, 2006). No entanto a identificação de outros textos presentes em uma produção irá depender do conhecimento de mundo do leitor, o que auxiliará na construção de sentidos (Koch; Elias, 2006). A partir do conceito de dialogismo, cunhado por Bakthin (1920), surgiu o conceito de intertextualidade proposto por Kristeva (1969). Já a polifonia é um termo mais abrangente, a intertextualidade está incluída na polifonia. A partir 
das notícias e dos artigos de opinião, trabalhamos a construção de sentido por meio dos verbos, nas primeiras para marcar "imparcialidade" e nos segundos para marcar o posicionamento. O tema, os gêneros textuais e as análises linguísticas foram pensados para que o projeto de ensino fosse todo conectado.

\section{Metodologia}

A metodologia foi baseada em uma pesquisa ação-crítica, já que houve um ciclo a partir de um problema inicial, aulas de Língua Portuguesa descontextualizadas, pensamos estratégias, aplicamos e as avaliamos criticamente. Para refletirmos sobre a elaboração do projeto de ensino, houve várias etapas. A primeira foram as leituras relacionadas à Neuroeducação e ao Ensino de Língua Portuguesa. A segunda consistiu em contatar a escola e verificar os interesses dos alunos e, a partir de então, elaboramos critérios para a elaboração do projeto. Por fim, analisamos criticamente as atividades elaboradas para o projeto.

\subsection{Critérios para a elaboração do projeto de ensino}

A partir das leituras relacionadas à Neurociência cruzadas com as informações acerca da turma, estabelecemos critérios para a elaboração e aplicação do projeto de ensino.

Quadro 1: Critérios para elaboração de atividades do projeto de ensino.

\begin{tabular}{|c|c|}
\hline CRITÉRIO & ATIVIDADE \\
\hline $\begin{array}{l}\text { Aprendizagem que seja } \\
\text { significativa: aprendemos } \\
\text { mais quando nos } \\
\text { emocionamos }\end{array}$ & $\begin{array}{l}\text { Escolha do tema de } \\
\text { acordo com os interesses } \\
\text { dos alunos. }\end{array}$ \\
\hline Trabalho com o texto & $\begin{array}{l}\text { Escolha de gêneros } \\
\text { diversificados. Análise } \\
\text { linguística de acordo com } \\
\text { o gênero textual. }\end{array}$ \\
\hline $\begin{array}{l}\text { O reforço na memória é } \\
\text { fundamental para a } \\
\text { aprendizagem }\end{array}$ & $\begin{array}{l}\text { Tratamento de um mesmo } \\
\text { tema de formas diferentes. }\end{array}$ \\
\hline $\begin{array}{l}\text { Trabalho para } \\
\text { desenvolver as funções } \\
\text { executivas }\end{array}$ & $\begin{array}{l}\text { Estabelecimento de } \\
\text { pequenas metas e } \\
\text { desafios em curto prazo. }\end{array}$ \\
\hline
\end{tabular}

\begin{tabular}{|c|c|}
\hline $\begin{array}{l}\text { Desenvolvimento } \\
\text { aprimoramento } \\
\text { consciência política }\end{array}$ & $\begin{array}{l}\text { Escolha do tema e dos } \\
\text { gêneros textuais. }\end{array}$ \\
\hline Uso de tecnologias & $\begin{array}{l}\text { Produção final dos alunos, } \\
\text { um programa humorístico. } \\
\text { Para que o programa } \\
\text { fosse produzido foram } \\
\text { usadas câmeras } \\
\text { filmadoras além de } \\
\text { programas para a edição } \\
\text { do mesmo. }\end{array}$ \\
\hline $\begin{array}{l}\text { Trabalho com as } \\
\text { habilidades de escuta, de } \\
\text { fala, de escrita e de } \\
\text { leitura. }\end{array}$ & $\begin{array}{l}\text { Diferentes gêneros } \\
\text { textuais produzidos pelos } \\
\text { alunos ou trazidos pela } \\
\text { professora. }\end{array}$ \\
\hline $\begin{array}{lr}\text { Desenvolvimento } & \text { da } \\
\text { habilidade } & \text { de } \\
\text { argumentação } & \text { dos } \\
\text { alunos, valorização } & \text { das } \\
\text { ideias dos mesmos. } & \end{array}$ & $\begin{array}{l}\text { Momentos de debate } \\
\text { sobre os temas } \\
\text { trabalhados em cada aula. } \\
\text { Gêneros textuais que } \\
\text { evidenciem } \\
\text { argumentação, essa } \\
\text { artigo de opinião e debate. }\end{array}$ \\
\hline $\begin{array}{l}\text { Valorização } \\
\text { interdisciplinaridade }\end{array}$ & $\begin{array}{l}\text { Pesquisa sobre fatos } \\
\text { históricos relacionados ao } \\
\text { tema. Leitura de um autor } \\
\text { renomado da Literatura, } \\
\text { José Saramago. }\end{array}$ \\
\hline $\begin{array}{l}\text { Estabelecimento } r \\
\text { relação entre gêneros } \\
\text { textuais }\end{array}$ & $\begin{array}{l}\text { Comparação entre notícias } \\
\text { faladas e } \quad \text { escritas. } \\
\text { Comparação } \\
\text { entre romance e filme. }\end{array}$ \\
\hline $\begin{array}{l}\text { Reflexão sobre } \\
\text { conceito de texto }\end{array}$ & $\begin{array}{l}\text { Textos imagéticos, } \\
\text { falados, além do texto } \\
\text { escrito. }\end{array}$ \\
\hline $\begin{array}{ll}\text { Conexão } & \text { entre } \\
\text { atividades } & \end{array}$ & $\begin{array}{l}\text { Nosso cérebro seleciona } \\
\text { assuntos de forma } \\
\text { conectada, portanto, se as } \\
\text { atividades estiverem } \\
\text { conectadas, é provável } \\
\text { que seja mais fácil sua } \\
\text { rememoração. }\end{array}$ \\
\hline Reflexão sobre autoria & $\begin{array}{l}\text { Os alunos deverão } \\
\text { produzir textos e perceber } \\
\text { que estes são valorizados, } \\
\text { eles deverão se sentir } \\
\text { autores. }\end{array}$ \\
\hline
\end{tabular}

Fonte: elaboração própria

\subsection{Participantes}

A turma que participou da aplicação do projeto de ensino frequenta uma escola pública da cidade de Bagé, no estado do Rio Grande do Sul. Há 30 alunos (17 meninos e 13 meninas), e as idades variam entre 15 e 19 anos.

\subsection{Materiais utilizados}

A diversidade de materiais é uma característica fundamental deste projeto, já que a variedade de estímulos é importante para trabalhar os aspectos da 
atenção, da motivação e, consequentemente, para o estabelecimento dos conhecimentos na memória. 0 projeto abarcou 18 horas/aulas.

\section{Resultados e análises}

Nesta seção, serão apresentados os resultados em três diferentes etapas: (1) fluxogramas exemplificando atividades do projeto de ensino ${ }^{2}$, (2) as inferências durante a aplicação do projeto de ensino e (3) o teste pós-aplicação para verificação de consolidação na memória por meio de uma roda de conversa orientada.

Apresentamos as atividades e habilidades trabalhadas com relação às funções executivas e memória, resumidas em fluxogramas.

Fluxograma 1: Atividades para o desenvolvimento das funções executivas

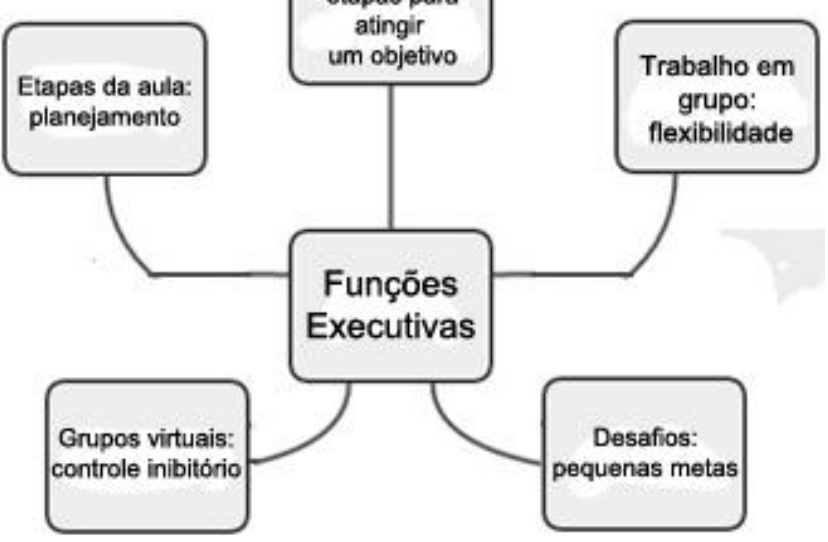

Fonte: elaboração própria

O trabalho com as funções executivas foi realizado por meio da divisão da produção final dos alunos em pequenas etapas, que seriam concluídas ao longo de todo o projeto de ensino como, por exemplo, a construção de um roteiro. O trabalho em grupo também foi uma forma de trabalhar a capacidade de colaboração, já que a produção final era em grupo. Evidenciar as etapas de cada aula, que ficavam no quadro negro, também ajudou no trabalho

\footnotetext{
${ }^{2}$ Para ver o projeto de ensino em sua versão integral, ler (AZAMBUJA, 2014).
}

com as funções executivas, já que o aluno pode planejar-se de acordo com o que seria desenvolvido.

Outro recurso utilizado foram grupos virtuais, os quais serviam para trabalhar o controle inibitório, já que eles perdiam ou ganhavam pontos conforme os comportamentos e atividades realizadas. Outra estratégia encontrada para o trabalho com as funções executivas foram os desafios: toda aula os alunos tinham um desafio a cumprir, o que significava pequenas metas ao longo de todo o projeto de ensino. Essa estratégia ajudou a trabalhar aspectos importantes relacionados às funções executivas, tais como planejamento e estabelecimento de um objetivo.

Com relação à memória, foram trabalhadas as seguintes atividades:

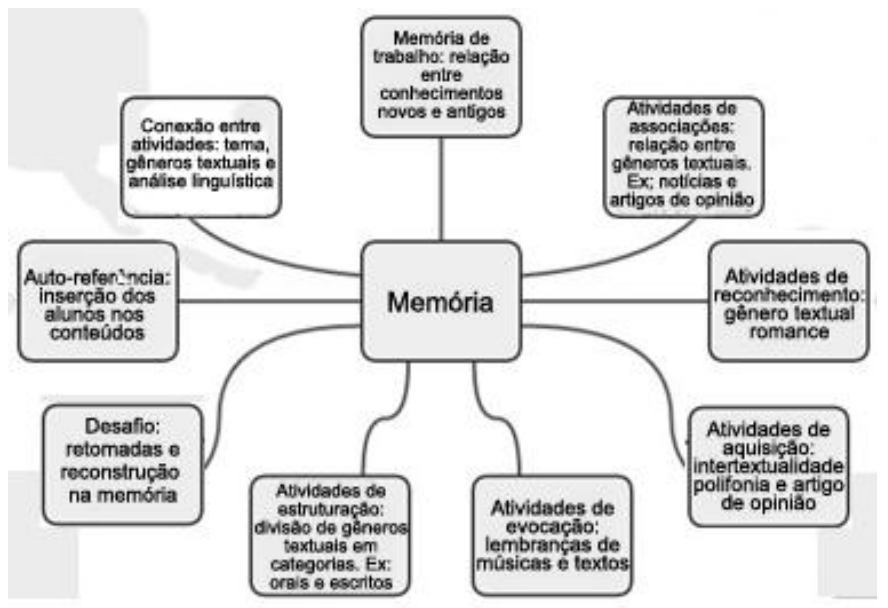

Fluxograma 2: Estratégias para a consolidação dos conteúdos na memória

Fonte: elaboração própria

O nosso cérebro seleciona as informações de forma conectada; portanto, acreditamos que pensar em todo o projeto da mesma forma possa ter auxiliado na consolidação da memória por meio do tema, gêneros textuais e análise linguística. A relação entre os conhecimentos novos e os antigos também é primordial para trabalhar a memória de trabalho e reforçar conexões entre as memórias. Também trabalhamos com atividades que enfocassem diferentes processos da memorização, tais como: associação entre gêneros textuais diversos, como notícias e reportagens, reconhecimento de gêneros textuais já conhecidos como o romance, aquisição de 
novos conhecimentos, como as características de um artigo de opinião, evocação de conhecimentos que os alunos adquiriram durante o projeto de ensino, como a intertextualidade, e estruturação de gêneros textuais orais e escritos. Outra forma de trabalhar a memória foi por meio dos desafios, já que os alunos faziam retomadas dos conteúdos trabalhados em aula.

\subsection{Inferências durante a aplicação do projeto}

Na primeira aula, percebemos o interesse dos alunos pelo tema, em especial sobre as "manifestações populares". Ainda não havíamos mencionado o tema do projeto de ensino, apenas executamos a música "Até quando?", do Gabriel O pensador, para que os alunos ouvissem, e o tema já surgiu espontaneamente.

Com relação aos aspectos da Neurociência, usamos de diferentes estratégias para trabalhá-los. Umas delas foram os desafios que deveriam ser cumpridos em toda aula. Pudemos perceber que, no início, mostraram-se resistentes e só alguns grupos os cumpriam. No entanto, ao longo do projeto de ensino, os alunos mostraram-se mais comprometidos. Todos os grupos cumpriam os desafios e, assim, pudemos inferir que as funções executivas pensadas para essa atividade foram trabalhadas de forma eficaz.

Outra estratégia adotada foi a diversidade de estímulos para a captação e recaptação da atenção dos alunos em aula. Durante o projeto, ampliamos a utilização de vídeos, já que pudemos perceber que era algo que realmente cativava os alunos e os mantinha atentos.

Com relação ao aspecto da emoção, o tema por si só era algo que despertava as emoções dos alunos e, quando envolvia humor, isso se amplificava, já que era uma turma muito crítica, mas também muito divertida. Ainda com relação à emoção, pudemos perceber uma relação de proximidade dos alunos para conosco e isso foi fundamental para que os alunos se sentissem envolvidos emocionalmente com o projeto de ensino.
Quanto à motivação, sempre procuramos valorizar as atividades que realizavam, também procuramos valorizar o que tinham de melhor. Ao se sentirem motivados, realizaram as atividades propostas e envolveram-se com o projeto como um todo.

O último aspecto é a memória, que trabalhamos por meio de retomadas, de conteúdos significativos e de inserção dos alunos no contexto dos conteúdos trabalhados. Percebemos que, ao fazer retomadas, de maneira geral, os alunos lembravam-se do que havia sido trabalhado.

\subsection{Roda de conversa orientada}

A roda de conversa orientada foi pensada com intuito de obter indícios de consolidação na memória do projeto de ensino como um todo, além da verificação da aplicabilidade do trabalho com as funções executivas nos processos de ensino e de aprendizagem.

Foi realizada na escola, todos os alunos da turma participaram, e a duração foi de aproximadamente cinquenta minutos.

Essa atividade aconteceu cinco meses após a finalização do projeto de ensino por meio de uma conversa com tópicos definidos, tais como: a pertinência do tema, a análise linguística no cotidiano dos alunos, as estratégias e metodologias do projeto como um todo. As perguntas norteadoras da roda de conversa orientada encontram-se em anexo.

O principal objetivo do projeto de ensino era fazer com que os alunos olhassem para a política e para os meios de comunicação de forma mais crítica e, durante a roda de conversa, foi-lhes solicitado que falassem sobre se sua visão tanto da política quanto da mídia havia mudado. Os alunos, de maneira geral, falaram que sim, que não costumavam pensar sobre esse assunto, no entanto, após esse projeto, ficaram mais atentos a essas questões.

(2) Comentário do aluno João ${ }^{3}$

\footnotetext{
${ }^{3}$ Pseudônimos criados para proteger a identidade dos alunos.
} 
"Agora eu penso sobre a imparcialidade, que eles (mídia) dizem que têm, mas a gente sabe que não funciona assim."

Com relação às atividades e conteúdos, perguntamos se os alunos conseguiam relacioná-los. Todos responderam que sim, que todo o projeto de ensino foi conectado. Com relação ao tema, falaram que não imaginavam um tema melhor para ser trabalhado.

\section{(3) Comentário do aluno André}

"Foi o melhor tema, porque era o foco da mídia na época."

Para verificar o trabalho com as funções executivas, perguntei se gostavam de cumprir os desafios e se fariam, caso fosse só mais um tema para casa. Responderam que se fosse considerado uma tarefa para casa não os fariam.

(4) Comentário do aluno José

"Era legal, porque sabíamos mais sobre o assunto."

(5) Comentário da aluna Maria

"Gostava dos desafios, porque sou competitiva."

(6) Comentário do aluno Marcelo

"Eu gostava porque ganhava os pontos. Isso me motivava a fazer."

Essas declarações são importantes, pois demonstram que os objetivos dos desafios foram cumpridos, já que, ao retomar os conteúdos, sabiam mais sobre o assunto, como apontou o aluno José. Os alunos Maria e Marcelo evidenciaram em seus comentários o quanto era motivador receber os pontos, uma forma de valorização do trabalho que realizavam. Esses pontos eram somente uma competição entre os grupos, não tinham relação com suas notas.

Após a roda de conversa, pudemos inferir que o trabalho com a Neurociência nos trouxe resultados satisfatórios nos processos de ensino e de aprendizagem, possibilitando que atingíssemos os objetivos inicialmente propostos no projeto de ensino.

\section{Considerações finais}

A Neurociência mostrou ser uma grande aliada no processo de construção e aplicação de um projeto de ensino articulando conhecimentos em Neuroeducação e em Língua Portuguesa. O objetivo da Educação é sempre o sucesso do aluno nos processos de ensino e de aprendizagem, e acreditamos termos nos empenhado em alcançar esse objetivo durante a aplicação do projeto e termos obtido alguns indícios de sucesso, como foi evidenciado nas inferências durante a sua aplicação.

Esta pesquisa foi importante para obtermos indícios que confirmem as hipóteses inicialmente pensadas nesse trabalho. Uma das hipóteses é de que o tema escolhido "política" vai ao encontro dos interesses dos adolescentes, que passam a refletir sobre conhecimentos mais abstratos, o que foi evidenciado durante a aplicação do projeto de ensino, considerando a motivação demonstrada pelos alunos.

Outra hipótese foi a de que, ao escolhermos os gêneros textuais e a análise linguística a partir de um tema central, o projeto tornar-se-ia todo conectado, o que facilitaria a memorização, já que o cérebro seleciona as informações de forma conectada. Ao retornar à escola e questionar os alunos sobre a conexão do projeto, eles afirmaram que todas as atividades eram conectadas, o que ajudava na compreensão. Além disso, a roda de conversa orientada aconteceu cinco meses após a finalização do projeto de ensino, e perceber que a maioria dos alunos lembrava das análises linguísticas trabalhadas em aula corroborou essa hipótese.

Por fim, a última hipótese fazia menção à construção do projeto de ensino como um todo, pois, se considerarmos a maneira como o cérebro aprende, é provável que obtenhamos resultados mais satisfatórios nos processos de ensino e de aprendizagem. Portanto, ao pensar em atividades que captem e mantenham atenção por meio da diversidade de estímulos, que desafiem e motivem os alunos, que mexam com as suas emoções, que trabalhem os diversos tipos de memórias e que desenvolvam e/ou aprimorem as FEs, pensaremos 
em um projeto que respeita como se dá o funcionamento do cérebro. Um projeto que respeita o funcionamento cerebral terá mais chances de obter sucesso do que um projeto que vai de encontro ao funcionamento cerebral, o que ficou evidenciado nos resultados obtidos durante a aplicação deste projeto de ensino.

As limitações do trabalho e do projeto de ensino em si se dão na medida em que esse projeto não pode ser aplicado a toda e qualquer turma, ele foi pensado especificamente para essa turma. As ideias de maneira geral podem ser aproveitadas, no entanto para a sua aplicação é fundamental que ocorram adaptações de acordo com a realidade da turma em que será aplicado.

\section{Referências}

DUCROT, Oswald. Dire et ne pas dire: principes de semantique linguistique. Paris : Hermann. 1972.

FAUCONNIER, Gilles; TURNER, Mark. The way we think. New York: Basic Books. 2002.

FELTES, Heloísa Pedroso de Moraes. Semântica Cognitiva: ilhas, pontes e teias. Porto Alegre: EDIPUCRS. 2007.

FILLMORE, Charles J. Frame semantics. In: Linguistic Society of Korea (eds.). Linguistics in the morning calm. Seoul: Hanshin. 1982, p. 111-137.

LAKOFF, George; JOHNSON, Mark.Metaphors we live by. Chicago: The University of Chicago Press. 1980.

LEVINSON, Stephen C. Pragmatics. Cambridge: Cambridge University Press. 1983.

LYONS, John. Semantics. Cambridge: Cambridge University Press. 1996.

SALINGER, Jerome David. The Catcher in the Rye. New York.Little, Brown and Company. 1951.

SEARLE, John. Speech acts. Cambridge: Cambridge University Press. 1969. (JORNAL FOLHA DE S. PAULO, 13/01/2014, p. 2 - artigo de Gustavo Patu). 